\title{
NUESTRO HUSO HORARIO ES INOCENTE. INCONVENIENTES DE UN CAMBIO DE HUSO EN ESPAÑA
}

Jorge Mira Pérez

Universidade de Santiago de Compostela

Doi: 10.17075/enhhp.2017.001 


\section{INTRODUCCIÓN}

El debate sobre el huso horario español (y, por tanto, considerar al actual como un problema) apenas existía hasta principios del siglo xxi. A partir de ese momento, y sobre todo a lo largo de la última década, se ha colado con intensidad en nuestro país, movido principalmente por la Asociación para la Racionalización de los Horarios Españoles (Arhoe), que también se identifica como «Comisión Nacional para la Racionalización de los Horarios Españoles y su Normalización con los demás países de la UE» (constituida con anterioridad y que es el embrión de la asociación).

Esta asociación ha generado una serie de ideas-fuerza que, hábilmente difundidas, han llegado a instalarse en la mayoría de las redacciones de los medios de comunicación españoles, al punto de que muchas de las noticias sobre este tema han sido redactadas sobre la base de los recursos distribuidos por Arhoe.

El 10 de octubre de 2013, la Subcomisión de Racionalización de Horarios, Conciliación y Corresponsabilidad del Congreso de los Diputados publicó sus conclusiones. En medio de una prolija descripción de propuestas dedicadas a medidas de conciliación y organización empresarial, aparecía una alusión al cambio de nuestro huso horario, atribuyéndole unos supuestos efectos sobre la mejora de nuestras vidas que, según se intentará explicar en el presente capítulo, no tienen fundamento.

El informe de esa Subcomisión, junto con el momento de volatilidad política vivido poco después, conllevó que algún partido político lo empezase a incluir en su programa político, medida que pronto se extendió a otros del arco parlamentario.

Hoy se puede decir que, tras estos últimos años, se ha abierto la caja de Pandora del huso. Se constata sobre todo en las amplias discusiones que tienen lugar en los dos cambios horarios estacionales, en las que se confunden cuestiones que 
son diferentes (el huso por un lado y el cambio horario estacional por otro). Pero el peligro de esta dinámica se ha percibido de modo más agudo en fecha reciente, tras sendas declaraciones de los parlamentos balear y valenciano apoyando (por unanimidad de ambas cámaras) la permanencia del horario de verano todo el año, lo que en realidad implicaría situarse en el huso horario UTC+2 (UTC= tiempo universal coordinado, estándar de tiempo universal).

$\mathrm{Si}$ esto se considera digno de mención es porque UTC+0 corresponde a la zona horaria de Greenwich; es decir: lo propuesto por esos dos parlamentos regionales llevaría a esas dos comunidades a una zona horaria separada dos horas de la de Reino Unido y Portugal. El hecho de que varios de los partidos políticos que han contemplado la propuesta de pasar España al huso UTC+0 apoyen ahora, en esas comunidades, una medida diametralmente opuesta (el paso a UTC+2) demuestra a las claras el estado de confusión existente y el peligro que supondría tomar decisiones políticas de este calibre en dicho estado. También pone de manifiesto que nuestro huso actual, UTC+1 (el único que ha conocido el $95 \%$ de la población española y al cual se ha adaptado tras muchos años), es la opción centrada, frente a quienes quieren modificarlo, restando o sumando, con idénticas promesas mágicas (e incompatibles entre sí).

\section{CAMBIAR EL HUSO HORARIO NO SERVIRÍA PARA NADA}

Muchos de los defensores del cambio de huso horario en España piden que la hora oficial española pase a ser la UTC+0, como en el Reino Unido o Portugal. Para fijar con claridad este asunto a nivel práctico, esa medida implicaría que, si Ud. mira la hora ahora mismo, el cambio consistiría en darle para atrás una hora a su reloj.

Para un físico o un matemático ese acto corresponde a una operación habitual llamada «cambio de variable». Este nombre no esconde más que un rebautizo de los números usados para describir un fenómeno, pero teniendo claro que las propiedades medidas del fenómeno en sí no van a cambiar con esa operación estética.

Le pongo un ejemplo: si va la Puerta del Sol en Madrid, verá en una zona del suelo una placa en la que reza:

«Kilómetro 0. Origen de las carreteras radiales». 
Esas carreteras radiales de España marcan ahí su punto de partida. Con esa referencia, A Coruña está más o menos en el punto kilométrico 600 a partir de ese origen. Un cambio de variable, análogo al cambio de huso horario, consistiría en asignarle un número distinto al punto kilométrico de la Puerta del Sol.

Imaginemos que le asignamos a ese punto el valor «kilómetro 100». ¿Estaría A Coruna $100 \mathrm{~km}$ más cerca? No, porque al redefinir ese origen y asignarle un nuevo número, en el punto correspondiente de A Coruña pasaría a figurar el kilómetro $700(600+100)$. Se hace hincapié en este hecho para señalar que la distancia entre esos dos puntos es la resta de los valores nominales de los dos puntos kilométricos, de modo que, por mucho que se cambie el valor asignado al origen, la distancia no va a variar. El valor del punto kilométrico no tiene sentido en sí mismo, solo tiene sentido cuando es usado para ser restado a otro medido en el mismo sistema de referencia. Por supuesto, no cambiarían ni la distancia ni ninguna otra circunstancia relativa al tráfico (por ejemplo, el número de accidentes en el país no se alteraría por el mero hecho de desplazar ese valor de referencia de la Puerta del Sol).

Eso sí, si por alguna circunstancia se hiciere un cambio del «huso kilométrico» en la Puerta del Sol, esa operación arrastraría la renumeración de miles de puntos kilométricos, con un coste ya no solo material, sino derivado del despiste para la población, que no asimilaría esos nuevos puntos kilométricos de modo instantáneo (imagine el caso de aquellos profesionales que pactan citas indicando como referencia tal o cual punto kilométrico).

Pues algo similar ocurriría con un cambio de huso horario español. ¿Cómo visualizar el efecto de esa medida? Indiquemos cómo afectaría a un ciudadano de a pie.

Supongamos que ese ciudadano tiene un pequeño comercio, que abre de 9:00 a 14:00 y de 16:00 a 19:00 horas. Como todo el mundo, quiere mejorar su calidad de vida. Ha oído algo del huso horario, que según parece es culpable en parte de sus males: «Espańa cae en la zona de Greenwich del mapa horario y estamos malditos por no tener la hora británica», «Portugal tiene el huso británico, y nosotros no: algo no encaja», «los españoles vivimos de noche», «somos víctimas de los juegos de Hitler y Franco con el reloj», etc.

El mensaje que le llega de casi todas partes es el mismo: "pongámonos en el huso del Reino Unido y curaremos la anomalía horaria española», y para colmo los principales partidos políticos han comprado la idea. 
Ante ese estado de opinión, parece claro que ese ciudadano recibirá con los brazos abiertos el cambio de huso.

Ilustremos la situación con un día en el que el Sol se pone a las 19:00 (véase figura 1). Eso quiere decir que, cuando nuestro ciudadano baja la persiana de su comercio, ve ponerse el Sol. Supongamos ahora que al día siguiente el Gobierno ejecutase el cambio al huso británico.

¿Qué ocurriría ese día? Cuando nuestro amigo fuese a cerrar la persiana se encontraría que ya es de noche. El Sol se habría puesto hace una hora, a las 18:00. En eso consiste el cambio: en asignar a los hechos naturales una hora menos de la que tenían antes...

... Y esto nos lleva a la primera consecuencia tangible de ese cambio de huso: al igual que le ocurriría a ese ciudadano, toda la vida del país se desplazaría una hora hacia la noche.

Es paradójico que quienes defienden la medida argumenten que la toman para curar la supuesta anomalía horaria española, que hace que «los españoles vivamos de noche». Es obvio que el resultado, a pelo, va en el sentido diametralmente opuesto. Con todo, estos grupos intentan vender como supuesta ventaja otra medida que proponen adoptar al mismo tiempo: adelantar los horarios de cierre una hora.

Dicho así («salir antes del trabajo»), la medida parece un regalo, pero en realidad esconde un juego propio de trileros.

Veamos qué ocurre.

Al ciudadano se le adelantaría el momento de cierre una hora. Es decir, en vez de cerrar a las 19:00 cerraría a las 18:00. Así, cuando llegasen las 18:00 de la nueva hora oficial, bajaría la persiana de su negocio; pero... miraría al horizonte y vería... el Sol poniéndose, ¡tal y como sucedía antes de todas estas medidas!

Su reloj marcaría una hora distinta, sí, pero nada habría cambiado. De hecho, pronto se percataría del nulo efecto en la configuración de su jornada laboral. Si antes era de 9:00 a 14:00 y de 16:00 a 19:00, ahora tendría que abrir de 8:00 a 13:00 y de 15:00 a 18:00. Trabajaría las mismas horas, en las mismas condiciones y la evolución de su jornada con el recorrido del Sol sería exactamente la misma de antes. 


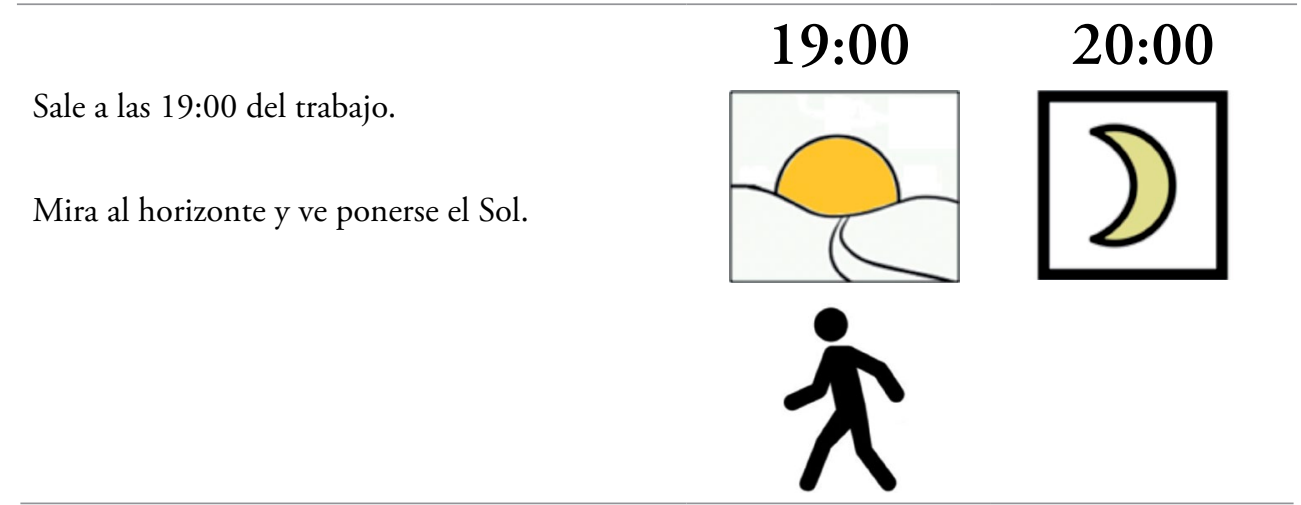
Aldis sionsente
Al día siguiente, el Gobierno decreta el retraso al huso horario británico.
El Sol, que antes se ponía a las 19:00, ahora lo hace a las 18:00.

Sale del trabajo como siempre a las 19:00 y descubre que ya es de noche.

PRIMERA CONSECUENCIA DEL CAMBIO DE HUSO: LA VIDA DEL PAÍS SE DESPLAZA AUTOMÁTICAMENTE UNA

HORA HACIA LA NOCHE.

\section{8:00 \\ 19:00}
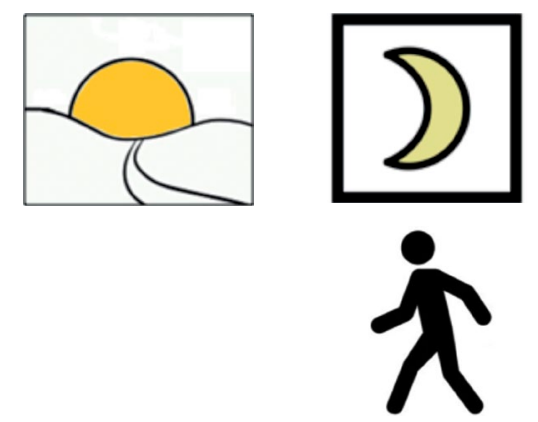

Para compensarle, se le adelanta una hora la salida del trabajo. Saldrá a las 18:00

Resultado: sale del trabajo, mira el horizonte y ve ponerse el Sol, exactamente como ocurría al principio.

NO HA CAMBIADO SU VIDA: RETRASAR EL HUSO $1 \mathrm{~h}$ Y ADELANTAR EL HORARIO 1 h ES UN JUEGO DE SUMA CERO. ESTÁ COMO ANTES.

\section{8:00}

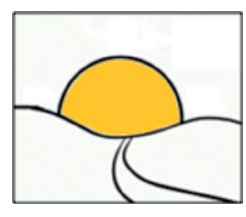

19:00

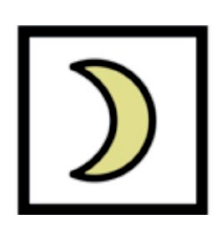

Figura 1: La inutilidad del cambio de huso. Al pasar a UTC+0, las actividades tienen lugar 1 hora más tarde respecto al Sol. Al compensar con el adelanto de horario, la actividad vuelve al mismo punto del que partía. Todo seguiría como antes, la situación no cambiaría. 
La operación es ridícula: retrasar una hora el punto de referencia horaria (huso) y adelantar una hora los horarios... para quedarnos exactamente en el mismo sitio. El único cambio: el número que marcaría el reloj para cada fase del día sería una unidad menor.

En la experiencia del autor de este artículo, ese es el principal obstáculo pedagógico a la hora de explicar la inutilidad del cambio de huso: la falta de percepción de que la combinación de ese cambio estético de la hora marcada por el reloj y el adelanto de los horarios no tendría ningún efecto en la vida de los españoles.

Además el eslogan dicho a pelo es seductor: «horarios hasta las 18:00 y huso de Portugal», se llegó a decir en campaña electoral. Cuando escuche eso, tenga claro que es lo mismo que «horarios hasta las 19:00 con nuestro huso horario actual».

En este punto cabría plantearse: «si con ese juego de suma cero nos quedamos igual, tampoco habría mucho riesgo por probar».

Sí que lo habría, ya que ese planteamiento está olvidando el coste de la transición, de modo análogo a lo que ocurría en el ejemplo de los puntos kilométricos. El cambio de huso se haría de golpe, pero la sociedad no iría ajustando (adelantando) sus horarios automáticamente, configurando un caótico viaje de vuelta a nuestro ritmo solar natural. Posiblemente empezasen adelantando horarios las grandes empresas y algunos organismos oficiales, pero el proceso se iría escalonando durante meses o incluso años, hasta converger a la misma situación en la que estamos actualmente.

Como variación en este juego de suma cero, Arhoe le propone a nuestro ciudadano «acortar una hora el período de descanso entre comidas», es decir, marcar para nuestro amigo un horario de 9:00 a 14:00 y de 15:00 a 18:00 horas (reducir el descanso para comer en una hora). Pero a esto hay una objeción evidente: esa medida no tiene nada que ver con el cambio de huso ni lo necesita, ya que se puede aplicar sin necesidad de cambiarlo. Lo mismo rige, por supuesto, para aquellos horarios que necesiten algún tipo de corrección: de ser así, cámbiense simplemente los horarios. Una cosa son los horarios y otra distinta el huso. Modificar los horarios es una operación que nada tiene que ver con el huso. 


\section{LAS FALACIAS USADAS PARA JUSTIFICAR UN CAMBIO DE HUSO}

Por si fuese poca la dificultad de explicación de los argumentos anteriores, se añaden usualmente al debate argumentos falaces. De entre ellos se destacan los siguientes:

\section{1. ¿El Sol es Greenwich y no Alemania?}

Este argumento, oído en campaña electoral, es el principal argumento de los defensores del cambio de huso. Se ilustra con un mapa plano del mundo, dividido en dos mitades por el meridiano de Greenwich, que enseñan a España, Portugal y Reino Unido con una aparente y absoluta sincronía bajo la luz del Sol y al resto de Europa bajo la oscuridad.

Ocurre, sin embargo, que la Tierra no tiene su eje de rotación alineado con respecto al Sol (ese eje sobre el que la Tierra gira sobre sí misma está desviado $23.5^{\circ}$ con respecto al eje de traslación alrededor del Sol). Esto implica que la manera en la cual el planeta es iluminado cambia a lo largo del ańo, o lo que es lo mismo, las duraciones del día y de la noche varían constantemente.

El momento de menor exposición solar, el día más corto del año, ocurre en el invierno. Dado que nuestro período de actividad está centrado en el día, esos días de invierno son los que establecen la pauta de nuestros horarios. Y dado que los horarios naturales del ser humano arrancan con el amanecer, se concluye pues que los amaneceres invernales son el punto natural de referencia mínima para establecer el inicio de la jornada.

¿Y cómo amanece en Europa en invierno? Si pudiésemos ver Europa desde el espacio en uno de esos amaneceres, la imagen sería la de la figura 2. La sorpresa surge al ver que la línea que separa la noche del día no se alinea con el Meridiano de Greenwich. Es más, sucede que esa línea sigue la inclinación del eje troncal que define el continente europeo.

El resultado: los europeos de la franja España-Francia-Alemania tenemos nuestros amaneceres sincronizados, o lo que es lo mismo, nuestros períodos de activación natural en invierno son más o menos los mismos. Es, por lo tanto, de lo más razonable que la Europa de esa franja España-Francia-Alemania (donde recae la mayor parte del peso europeo) tenga el mismo huso horario. Por ese mo- 
tivo, la referencia horaria actual es de lo más natural para un continente con la disposición geográfica europea. El Sol invernal, el que marca la referencia para el inicio de la actividad europea, es más Alemania que Greenwich.

\section{2. ¿Anochece muy tarde en España en verano?}

En el argumentario de los proponentes del cambio de huso suelen escucharse frases como «es imposible acostar a los niños en verano» o "estamos en un huso aberrante, no hay más que ver lo tarde que se pone el sol en verano».

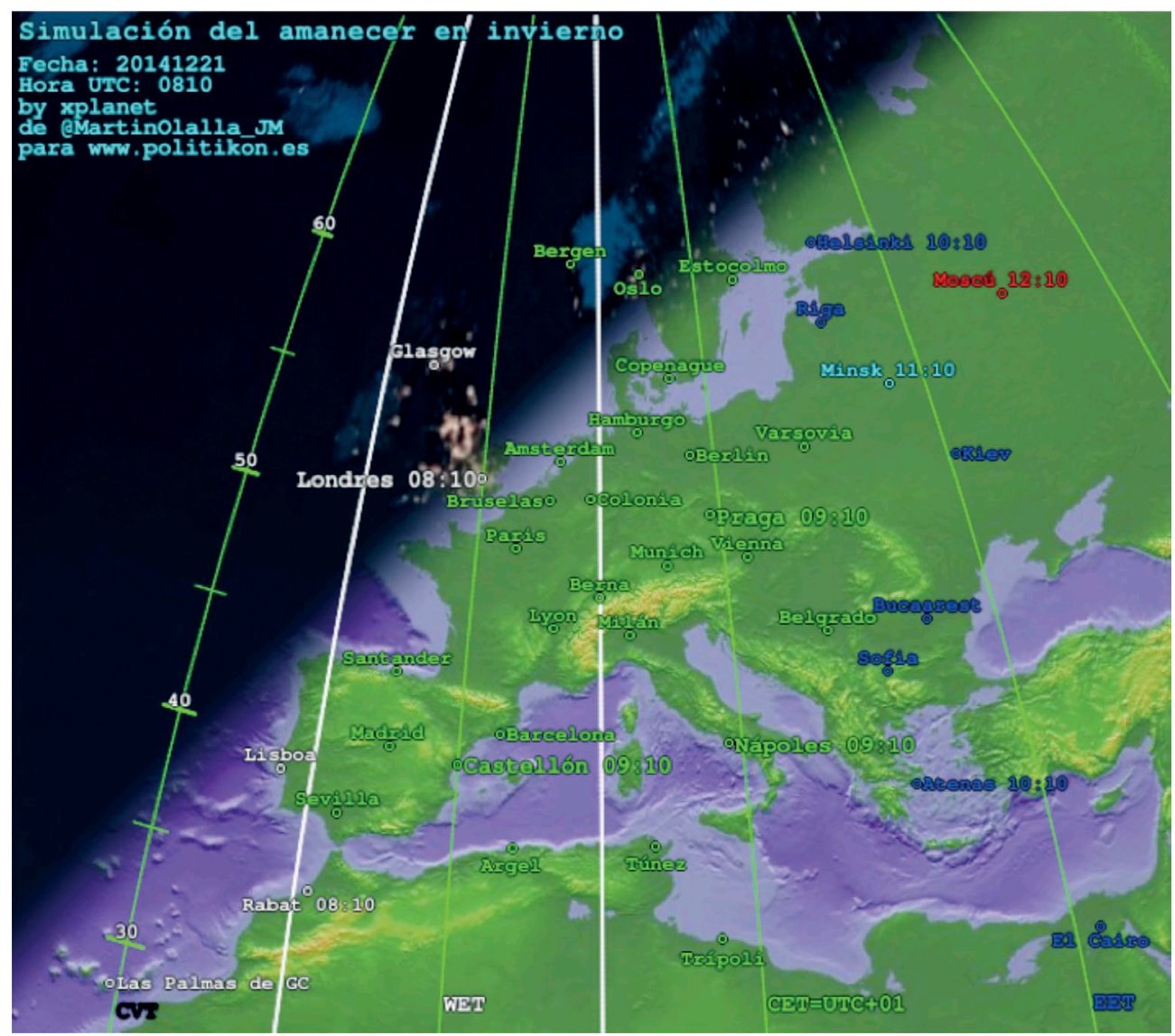

Figura 2: Aspecto del continente europeo en un amanecer invernal. La línea que separa el día de la noche sigue la inclinación natural del continente (figura cortesía de J. M. Martín Olalla). 
El anochecer del planeta Tierra es regulado por su rotación y posición respecto al Sol. Es por lo tanto de lo más obvio que se trata de un proceso natural, que en absoluto se va a ver modificado por el Boletín Oficial del Estado. Ocurre además que en el atardecer veraniego se produce la situación inversa al amanecer invernal: si pudiésemos ver Europa desde el espacio en uno de esos atardeceres, la imagen sería la de la figura 2 con los colores intercambiados (la zona oscura estaría iluminada y viceversa). En consecuencia, se concluye que el atardecer estival de los europeos está también sincronizado con el bloque central del continente, con el que compartimos el huso.

Esta circunstancia es, además, fácilmente constatable sin más que consultar horas de puesta de Sol en varias de las principales capitales europeas. Así, por ejemplo, el 1 de julio el Sol se pone a las 22:00 en París y Bruselas, a las 22:10 en Ámsterdam...

¿Y en Madrid? ¡A las 21:49!

Sí: en pleno verano el Sol se pone más tarde en las capitales de Francia, Bélgica y Países Bajos que en la capital de España. Lo de los supuestamente anómalos atardeceres españoles no es más que otra falacia.

Nuevamente, se recuerda que el cambio estético constituido por el pack «retraso de 1 hora de reloj + adelanto de 1 hora en la salida del trabajo» no haría más que dejarnos en la misma situación y, por lo tanto, España seguiría teniendo su misma relación con su atardecer.

\section{3. ¿No tenemos horarios europeos?}

Un mantra que, a base de ser repetido por los grupos que piden el retraso de nuestro huso horario, ha calado en la sociedad española, explotando nuestra secular tendencia a la autoflagelación. Nuevamente incurre en el gravísimo error de razonar sobre un mapa plano cuestiones que se deben explicar sobre una esfera. Tal y como se indicó en la sección 3.1, el hecho de tener la Tierra su eje de rotación desviado respecto al de traslación implica que la manera en la que el Sol ilumina Europa a lo largo del año cambia muchísimo. Entre otras consecuencias, la duración del día invernal decrece de manera acusada al movernos hacia el norte. Así, mientras que en el solsticio de invierno la duración del día en Madrid es de 9 h 17 min, en Londres es de 7 h 49 min (casi hora y media menos), en 
Berlín es de 7 h 39 min o en Estocolmo de 6 h 05 min (casi 3 horas y cuarto de diferencia con Madrid).

El 15 de diciembre anochece a las 14:45 en Estocolmo. Cuando un habitante de esa ciudad enciende la televisión en esa época para ver un partido de la Champions League (programado a las 20:45), llevará ya 6 horas de noche a sus espaldas, mucho más que cualquier español. A la vista está que no son situaciones comparables: el ritmo de un europeo del norte tiene unas limitaciones bastante distintas de las de un europeo del sur. La latitud, por su efecto determinante en la duración del día solar, es la que marca los ritmos de vida de los pueblos, no su huso horario, que es un convenio estético para asignar un número a cada momento del día.

Los pueblos se adaptan a su huso: una vez marcada la referencia horaria, elaboran sus horarios a partir de él en función de la situación solar correspondiente a su latitud. En las encuestas de uso del tiempo (aquellas que miden cuándo la población de un país realiza sus actividades diarias) se observa que las sociedades tienden a sentarse a comer $x$ horas antes del anochecer invernal [1] (véase figura 3). En el caso de la sociedad espańola, la hora promedio de la comida es 3-4 horas antes del anochecer y no presenta ninguna anomalía al compararla con la de otros países (figura 3), y eso no va a variar por cambiar el huso.

Tras el cambio de huso, esa hora de comida se acercaría 1 hora al anochecer y la sociedad española acabaría compensándolo adelantándola, convergiendo a la misma situación en la que estamos ahora (un proceso análogo al indicado en la figura 1), guiada por la secuencia día-noche propia de nuestra zona. Lo mismo se aplica para la hora de cena, que en las diferentes sociedades tiene lugar un determinado número de horas tras el anochecer.

Si en Santiago de Compostela el día de Navidad una familia se sienta a comer en torno a las 14:00 horas, eso supone hacerlo 4 horas antes del anochecer de ese día. Lo mismo ocurre para la cena, que sería en torno a unas 3 horas después del anochecer. Si se cambiase al huso horario británico, esa familia (viendo el acercamiento de la comida al anochecer) acabaría comiendo a las 13:00 horas, nuevamente 4 horas antes del anochecer de ese día (que tras el cambio de huso estaría produciéndose a las 17:00); es decir, la misma situación de antes (vuelve a producirse el proceso análogo al indicado en la figura 1). Lo mismo para la cena, que pasaría a comenzar en torno a las 20:00 h, 3 horas después del anochecer; es decir, una situación idéntica a la de antes. 


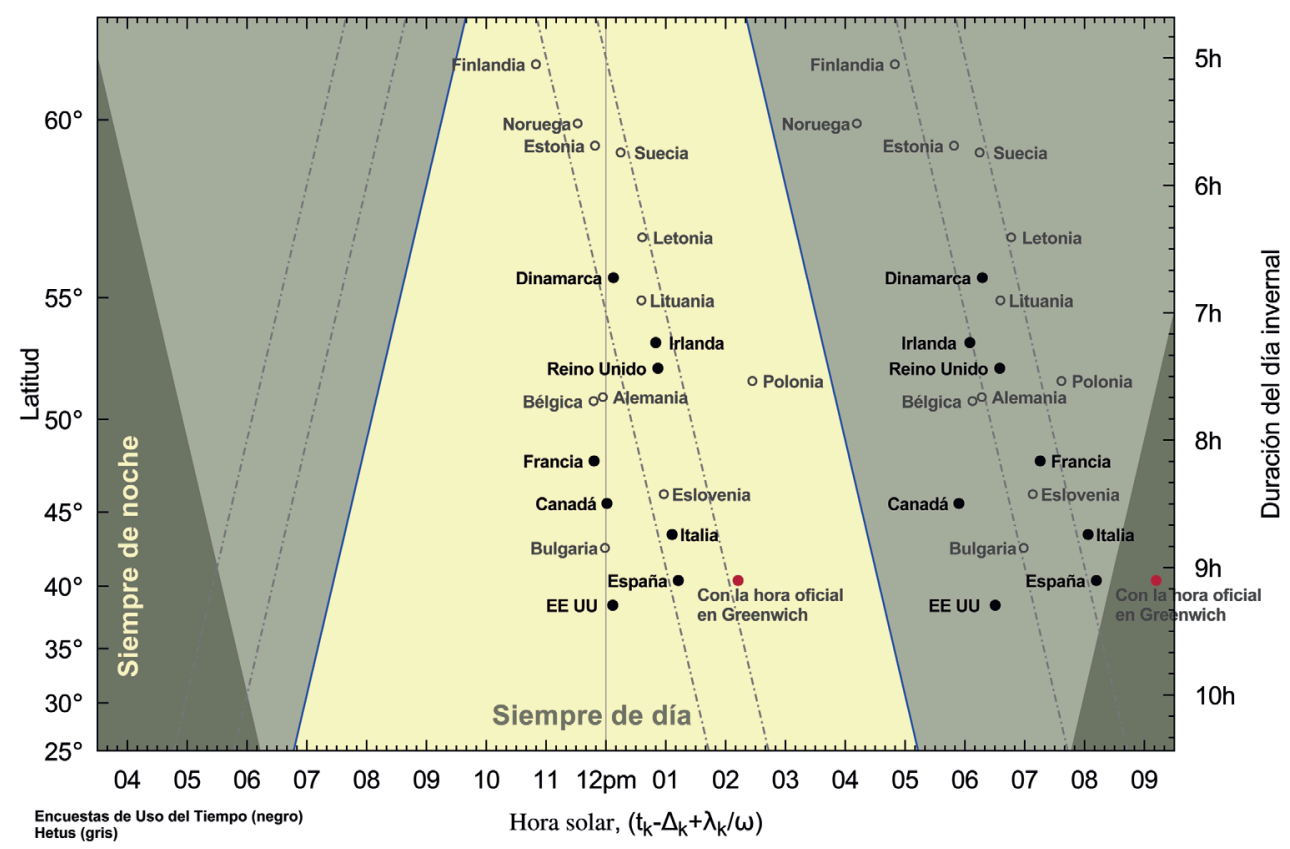

Figura 3: Horas promedio de comida y cena en diferentes países, en un diagrama que muestra su situación con respecto a los momentos de amanecer y anochecer mínimo y máximo. Tal y como se observa, España está en una situación normal. Nótese la disposición de los momentos de comida y cena con respecto a la línea del anochecer mínimo. Se indica dónde quedaría el momento de comida y cena tras un paso al horario de Greenwich (figura cortesía de J. M. Martín Olalla, véanse los datos en el cuadro I de la página 62).

Lo mismo se aplica a todas las demás facetas, como el prime time televisivo, que empieza en Italia y en España prácticamente en el mismo momento con respecto al anochecer.

Lo mismo se aplica a todas las demás facetas, como el prime time televisivo, que empieza en Italia y en España prácticamente en el mismo momento con respecto al anochecer.

En las jornadas realizadas en el Consello da Cultura Galega en octubre de 2016, que son el origen de este libro, José María Martín Olalla dejó bien patente esta circunstancia, con datos que demuestran cómo el discurrir de la vida de italianos y españoles sigue la misma curva a lo largo del día, al ser países de latitud parecida (véase [1]) y, por lo tanto, ritmo solar parecido. 
La mitad norte de Europa no tiene la suerte de disfrutar de la mayor homogeneidad de la iluminación solar a lo largo del año que tiene la mitad sur. La duración mínima de su día solar cae por debajo de las 8 horas, lo cual les hace imposible programar jornadas laborales realizables en período diurno.

No, su situación no es la nuestra. No cabe pues hablar de un «horario europeo».

\section{4. ¿Somos víctimas de un capricho de Franco y Hitler?}

Esta es, posiblemente, la falacia más sorprendente vertida en las discusiones sobre el huso horario; además con notable éxito, porque ha conseguido insertarse por defecto en muchas de las piezas que la mayoría de los medios de comunicación elaboran sobre el asunto.

Se desconoce quién es el introductor de este bulo, pero, dado que no se encuentra antes de 2008 ninguna referencia a él en internet, posiblemente fuese puesto en circulación ese año. Investigar y descubrir su origen es aún una tarea pendiente.

He aquí el contenido del bulo: supuestamente nuestro huso horario sería fruto de un gesto de pleitesía de Franco hacia Hitler en el curso de la II Guerra Mundial; una imagen de lo más potente, acompañada del mensaje de que la supuesta miseria horaria española es culpa de algo tan execrable como el nazismo.

La realidad es bien distinta: España sufrió casi una decena de cambios de hora oficiales (a veces de modo casi caótico) a cargo tanto del bando republicano como del nacional [2]. La hora de Berlín fue tan republicana como franquista. La II República desapareció, de hecho, bajo el huso horario de Berlín. Por si fuese poco, en contradicción con el relato construido, cuando Franco entró en Madrid, Barcelona y Valencia, suprimió en ellas el horario de Berlín y pasó al de Londres.

En marzo de 1940 se realizó un cambio al horario de verano que, simplemente, no tuvo vuelta atrás. Tal y como seńala Pere Planesas en [2] «[...] en la práctica, supuso un cambio permanente de la hora oficial de España adoptando, sin decirlo y, posiblemente, sin planearlo, la del huso horario $+1 »$. Ninguna pleitesía a Hitler. Ese supuesto vínculo nazi de nuestro huso simplemente no existe.

A partir de ese momento, España comenzó la adaptación a esa referencia horaria de modo natural. En una España atrasada (que desde luego no vivía bajo el signo de un reloj con la misma intensidad que ahora) el trauma no debió ser 
demasiado. Si se cambiase el huso horario en nuestros días, el coste del cambio sería muchísimo mayor. Además, tal y como se ha argumentado anteriormente, el modo de vida de los españoles acabaría convergiendo a la misma situación que tenemos ahora (y que es función de la latitud en la que vivimos).

En esa época Europa ya estaba inmersa en la II Guerra Mundial, un período que vivió múltiples cambios de horas oficiales de los contendientes (sin ir más lejos, el Reino Unido llegó a estar instalado en UTC+2, 1 hora más que España). $\mathrm{Al}$ acabar la guerra, varios de los países que habían adoptado el horario de Berlín se mantuvieron en él. Uno de ellos fue la Francia de Charles de Gaulle. Cinco años después De Gaulle impulsaría la CECA, el germen de lo que hoy es la UE, y posiblemente le pareciese una buena medida empezar esa unidad por el huso horario. En aquel momento Hitler y el régimen nazi ya no existían, así que se hace difícil sostener un alineamiento con ellos. España solo siguió la medida de su vecino más poderoso. Si alguien quiere poner apellidos al actual huso horario español, que diga que es gaullista y europeo.

¿Y Portugal? «O Portugal está malo España está mal». ¿Qué hay de esa típica frase? Portugal quedó anclado en la hora británica, así que sus marcas de referencia horaria no evolucionaron como las de España. Hoy, cada país está adaptado a su huso: la frontera horaria es virtual. Si cuando en España empieza el Telediario de las 21:00 h Vd. llama a un amigo portugués, oirá de fondo la sintonía del Telejornal de las 20:00. Si cuando viaja a Portugal deja Vd. la hora del reloj sin cambiar, y sigue más o menos la misma rutina horaria que en España, observará que no hay tanto cambio. Y, desde luego, las diferencias que perciba no serán debidas al huso horario.

\section{CONCLUSIÓN}

No existe la supuesta anomalía horaria española. Es un mito que se ha difundido sin el debido contraste con datos reales y se ha instalado como un mantra en nuestra sociedad. Es de la máxima urgencia para este debate aclarar las fuentes de dichas informaciones y la veracidad de los datos empleados. La objetividad científica ha brillado bastante por su ausencia. Es aún más grave, si cabe, la constatación de que en este debate se han introducido argumentos falaces. Sería interesante emprender alguna investigación sobre su origen. 
Tal y como se demuestra con los datos de uso del tiempo (encuestas generales que dibujan el ritmo del país), España tiene un ritmo de actividad similar al de otros países con latitud parecida (aunque tengan huso distinto). Latitudes diferentes implican ritmos de luz solar diferentes. Dado que las sociedades humanas reparten su actividad en función de la disponibilidad de luz solar, se debe ser cauteloso al comparar los ritmos de la Europa del norte con los del sur. El reparto de la actividad diaria de una sociedad depende de la duración de su exposición solar, no del huso que adopten como referencia.

Es de una evidencia palmaria que un retraso al huso británico desplazaría automáticamente toda la vida de España 1 hora hacia la noche (figura 1). No deja de ser asombroso que los defensores de esa medida afirmen querer «evitar que vivamos de noche», puesto que, paradójicamente, dicha medida no hace más que empeorar la situación. Se borda ya lo absurdo cuando se propone que, para compensar el efecto, "se adelantarían los horarios de salida del trabajo 1 hora»: la combinación del retraso de huso con el adelanto del horario hace que ambos movimientos se cancelen, dejando el ritmo diario de España tal y como está actualmente.

Es este un juego de trileros que confunde a la población y debe ser aclarado; la pedagogía es esencial en este debate. Es hasta cierto punto normal que una sociedad que vive bajo el reloj sacralice los dígitos que marcan sus agujas y por lo tanto pueda ser confundida por ciertos discursos. A la vista está que el típico mapa plano que representa las diferentes zonas horarias del planeta ha llegado a ser considerado erróneamente como un imperativo de igualdad de referencia horaria, so pena de graves consecuencias. Por esta razón, antes de cualquier debate, es necesario que la ciudadanía tenga meridianamente claro que las 19:00 de Madrid marcan exactamente el mismo momento que las 18:00 de Londres y Lisboa. Un acto a las 19:00 en España estará ocurriendo al mismo tiempo que un acto a las 18:00 de Londres o Lisboa. Una persona que sale del trabajo a las 19:00 horas en Madrid está saliendo al mismo tiempo que una que sale del trabajo a las 18:00 en Londres o Lisboa. Un programa de televisión que empiece en España a las 19:00 estará empezando al mismo tiempo que uno a las 18:00 del Reino Unido. Da lo mismo decir «19:00 de Madrid» que «18:00 de Londres», y no hay nada catastrófico en ello. Por muy ridículo que uno se sienta al repetir estas obviedades, la experiencia demuestra que es necesario.

Se debe advertir también del peligro de confusión de las operaciones de cambio de huso con las de cambio de hora estacional, realizadas dos veces al año en 
virtud de una Directiva Europea. El cambio estacional es debido a la gran fluctuación de horas de exposición solar en las zonas no tropicales (fluctuación que crece con la latitud) y busca centrar nuestra vida con el ritmo solar.

Una vez argumentado que un retraso de huso y adelanto de horario es una operación con resultado nulo, y también que el huso usado como valor de referencia no marca el ritmo de un estado, podría pensarse que nada malo habría en que un país cambiase a capricho su huso horario a las primeras de cambio.

La razón que lo desaconseja es el coste del cambio: el cambio de huso se ejecuta de golpe, pero la adaptación de un país de 46 millones de habitantes a esa nueva referencia no sería en absoluto directa. Hay ejemplos fallidos de este tipo de aventuras. El más destacable es el del Reino Unido, que de 1968 a 1971 adoptó el huso horario de España. El resultado fue un contundente fracaso, ya que la sociedad británica había fijado su referencia tras muchos años de vida con reloj, y no resistió la readaptación de dicha referencia.

Instalar a España en el huso horario del Reino Unido crearía un desbarajuste que tendría su coste y, lo que es peor, tras ese período de catarsis la sociedad espańola acabaría convergiendo a su ritmo natural, que viene marcado por su latitud y no por su huso. El huso horario no regula nuestras vidas.

\section{REFERENCIAS BIBLIOGRÁFICAS}

[1] Martín Olalla, José María (http://personal.us.es/olalla/time/santiago.pdf).

[2] Planesas Bigas, Pere: «La hora oficial de España y sus cambios», Anuario del Observatorio Astronómico de Madrid, 1 (2013), 373-402. 